\title{
A look back on the Prairie: the Manitoba Health Libraries Association / Manitoba Association of Health Information Providers (MHLA / MAHIP) chapter history project
}

\author{
Christine Shaw-Daigle, Lisa Demczuk, Angela Osterreicher, and Melissa Raynard
}

\section{Introduction}

The Manitoba Association of Health Information Providers (MAHIP) is the provincial chapter of the Canadian Health Libraries Association / Association des bibliothèques de la santé du Canada (CHLA / ABSC). MAHIP (formerly the Manitoba Health Libraries Association or MHLA) has been in existence since 1976, and in 2011 it will celebrate its 35 th anniversary as a professional association. Reaching this milestone inspired the membership to undertake a history project to better document the development and achievements accomplished throughout the life of the Association.

The focus of the project was to gather and organize the Association's documents, establish a digital repository of materials, and create a timeline that reflects the historical record of the Association. In so doing, the history project reflects a current wider interest in the history of library associations and how professional association activities parallel the growth and changing concerns of librarianship [1-4]. The MAHIP chapter history project has benefited from the examples of previously published chapter histories, including the history of the Northern Alberta Health Libraries Association (NAHLA) [5] and the useful CHLA Fact Sheet Reporting Your Chapter History: the Process [6] created by the NAHLA History Working Group. The challenges in locating, gathering, and organizing association documents and maintaining corporate memory will be familiar to many in volunteer-based organizations. MAHIP has been able to meet the challenges posed by the project, showcasing the chapter's history and better understanding its place within the context of health librarianship in Manitoba and Canada.

\section{Methods and description}

A working group, composed of the four members of the 2006-2007 MAHIP executive, was formed to gather, sort, and organize documents related to the creation, business, and activities of the Association. MAHIP documents were not all located in one central place or with one central person. To better locate and retrieve Association materials, an e-mail requesting that MAHIP (MHLA) documents be sent to a designated person was sent to all current and former members of the MAHIP (MHLA) executive and general membership. Once the materials were gathered, the working group carried out an initial sorting. Documents were first organized by Association years and placed in folders. The cumulated documents for each year were then scrutinized for type, scope, and quality, and obviously extraneous materials were discarded. With this task completed, the working group created an official guideline for the retention of MAHIP documents. The guideline require that two print copies, when possible, be kept and that retained materials should fall into one of the following categories:

1. Membership directory

2. Executive meeting agendas and minutes

3. Programme reports

4. Status reports on membership, finances, and strategic planning

5. Annual general meeting notice, nomination slate, biographies, agenda, minutes, financial statements, and President's report

6. Committee minutes, if any

7. Significant correspondence, other than newsletters and directories from other organizations

C. Shaw-Daigle. ${ }^{1}$ Hospital Librarian, University of Manitoba, Carolyn Sifton Helene Fuld Library, St. Boniface Hospital, Winnipeg, MB R2H 2A6, Canada.

L. Demczuk. Hospital Librarian, University of Manitoba, Victoria General Hospital, Winnipeg, MB R3T 2E8, Canada.

A. Osterreicher. Hospital Librarian, University of Manitoba, J.W.Crane Memorial Library, Deer Lodge Centre, Winnipeg, MB R3J 3M3, Canada.

M. Raynard. Hospital Librarian, University of Manitoba, Concordia Hospital, Winnipeg, MB R2J 3S8, Canada.

${ }^{1}$ Corresponding author (e-mail: Shaw-Daigle@umanitoba.ca). 
8. Photographs with copyright permission from the photographer (such as a signed letter authorizing reproduction), and background information such as when, where, who, etc.

9. MHLA newsletter and published documents

With the creation of the guideline, the working group sorted through the material again, organizing the documents within each Association year and removing irrelevant items. At this time, anything of significant importance to the chapter's history was noted for the creation of a historical timeline. Originally, the plan was to deposit the collection of documents with the Manitoba Archives, but after some investigation, the decision was made to deposit the Association's records with the University of Manitoba, Faculty of Medicine Archives, located in the Neil John Maclean Health Sciences Library. Established in 1974, the Archives works to acquire, preserve, and provide access to records created by the Faculty of Medicine, its departments, special programs, centres, institutes, as well as those archival materials created by organizations and individuals associated with the Faculty of Medicine.

PBWorks, a commercial collaboration service, was selected as the platform to create a wiki to serve as the MAHIP digital repository (http://mahip.pbworks.com). Selected core documents, such as the MAHIP constitution, newsletters, and other material reflecting the course of the Association's history were digitized and posted on this wiki. Personal reflections about the Association were solicited from past and present members and also added to the wiki.

\section{Results and outcomes}

From the initial collection, sorting, and organizing of Association documents, the MAHIP history project has resulted in the following outcomes: a retention policy for Association materials, an organized collection of documents for deposit in the University of Manitoba's Faculty of Medicine Archives, and a dynamic online repository of digitized materials and personal interviews. A timeline of achievement reflecting the highlights of the Association's history has been developed and a better appreciation for the challenges and successes experienced by the Association has resulted. A brief outline of the Association's history is included in Appendix A.

\section{Discussion}

Many challenges exist for small volunteer-based professional associations trying to retain documents and materials that inform the group's historical growth and achievements. By establishing a dedicated working group, creating a retention guideline, and drawing on examples of similar projects, MAHIP has successfully undertaken the process of discovery, organization, and preservation of the chapter's history. The organization of documents from the past 35 years and creation of a retention schedule has also secured the Association's legal, financial, and administrative accountabilities. Future plans for the project include ongoing deposit of documents to the University of Manitoba, Faculty of Medicine Archives, showcasing the history project to MAHIP members at a planned 35th anniversary event, and continuing to capture memories and reflections of Association members past and present. The MAHIP history project has resulted in an accessible and rich resource for the history of professional library associations and health librarianship in the province of Manitoba and Canada.

\section{References}

1. Clemons A, Goldberg T. Ohio valley group of technical services librarians: a history. Serials Review. 2007;33(2):103-13.

2. Jacobson S, Byrd GD. The Association of Academic Health Sciences Libraries: twenty-five years of excellence. J Med Libr Assoc. 2003;91(2):148.

3. Nilsen K. The Canadian association for information science: a look at its thirty-five-year history. Can J of Infor and Lib Sci. 2007;31(2):163-77.

4. Curran M, Krishan K. The Canadian library association serials interest group, 1980-1999. Serials Librarian. 2000;37(3):17-35.

-5. Chatterley T, Dorgan M, Clifford C, Chan L, Varney J, Dingwall O. Harnessing history: highlighting CHLA/ABSC capacity building through the Northern Alberta Health Libraries Association (NAHLA), 1985-2007. J Can Health Libr Assoc. 2008;29(2):51-4.

6. Dorgan M, Chan L, Chatterley T, Clifford C, Dingwall O, Varney J. Reporting Your Chapter History: the Process. Canadian Health Libraries Association Factsheet [monograph on the Internet]. Edmonton: Northern Alberta Health Libraries Association; 2007 [cited 18 Nov 2010]. Available from: http:// www.chla-absc.ca.

\section{Appendix A}

\section{A brief history of Manitoba Health Libraries Association / Manitoba Association of Health Information Providers (MHLA/MAHIP)}

Audrey Kerr, Medical Librarian from the University of Manitoba, with Isobel Steedman of the Manitoba Cancer Treatment and Research Foundation Library, held several informal meetings of health library workers in 1974. Momentum continued until 1976 when individuals working in the health sciences libraries' community in Manitoba received an invitation from Rena Kroeker, librarian at the Manitoba Association of Registered Nurses, to attend a meeting to explore a formal organizational structure [1-2]. The 21 attendees of the meeting on 20 October 1976 reflected the wide scope of health library settings and locations in Manitoba at that time, including the University of Manitoba, Winnipeg hospitals, schools of nursing, medical clinics, government agencies, and professional healthcare associations. A unanimous vote held at the meeting formalized the group into the Manitoba Health Libraries Association (MHLA) and elected Rena Kroeker as the association's first president. In the fall of 1978, MHLA became the fourth provincial organization to be given chapter status in the Canadian Health Libraries Association / Association des bibliothèques de la santé du Canada (CHLA / ABSC).

Several subcommittees were established at the beginning of the association's history, including a Current Awareness 
Committee, Program Committee, Union List of Serials Committee, and a Publication Committee [3]. In 1978, the Publication Committee produced the first issue of the Association's newsletter the Manitoba Health Libraries Association News. The newsletter continued its publication until 2000 and connected MHLA members across the province with news items from member libraries, updates of MHLA and CHLA / ABSC business, notices and reports of meetings, conferences, and professional development.

The varying fiscal and human resources of the Association's membership meant that resource sharing and cooperative ventures were a driving force for the activities of MHLA. At the very first meeting in 1976, it was decided that a combined list of journal holdings be created. This list of member holdings developed into the MHLA Union List of Serials in 1979. The MHLA Union List of Serials was regularly updated until it was no longer needed with the implementation of DOCLINE in 2002. The Association initiated the MHLA Union Book catalogue in 1982 and the MHLA Audio-Visual Union List in 1990. Reports from the Task Force on Shared Services created in 1980 evolved into the Winnipeg Health Information Network Trial Project (WHINET) in 1983. The trial would involve monthly workshops, MedLine demonstrations, instructional brochures, and an analysis of collection deficiencies and interlibrary loan patterns among Winnipeg's hospital libraries, the Manitoba Lung Association, several personal care homes, and others [4].

Continuing education for members was established early on as an important priority of the Association and remains so today. In the first years of the MHLA, general meetings were held three times a year and included a speaker that covered a continuing education topic; in addition, the Association sponsored invited speakers to the annual provincial conference of the Manitoba Health Organizations. In 1979, Joanne Marshall came from McMaster University to present on Clinical Librarianship. The Internet was presented to members in 1991. Other sessions included a DOCLINE workshop with Jim Henderson in 1995, an Internet searching course in 1998, a professional development session on "Electronic Reference" in 2002, and a mini-conference held in March 2003 featuring Susan Murray speaking on Strategies for Effective Consumer Health Communication. Finding Canadian Health Statistics was presented by Tom Flemming in 2004; the Books with Wings presentation in 2005 described the initiative by the University of Manitoba, including the Neil John Maclean Health Sciences Library, to bring medical publications to war-torn Afghanistan. Starting in 2005, the Association established a regular journal club for its members. In 2007, Creating the One-Shot Library Workshop by Jerilyn Veldof was given. A spring symposium will be held in 2011 on Virtual Realities - Information Pathways in a Digital World.

Throughout its 35 years, the Manitoba chapter has made contributions to CHLA / ABSC. Three national conferences have been hosted in Winnipeg; Rights and Responsibilities in 1983; Worlds to Explore in 1992, which saw the debut of the chapter gifts tradition for future CHLA / ABSC conferences; and, The Sky's the Limit in 2009. Many individual members have contributed to CHLA / ABSC by serving on various task forces and in a variety of positions, including board President, Vice President, Continuing Education Coordinator, and journal Editor. As well, CHLA / ABSC has recognized the contributions of several association members. Audrey Kerr received an honourary life membership; Judy Inglis received the Canadian Hospital Librarian of the Year in 1994 and the Special Recognition Award for dedication, contribution, and distinguished service in 2010 as part of the implementation team for the Canadian Virtual Health Library Initiative; and, Ada Ducas was honoured with the Margaret Ridley Charlton Award in 2008 for significant contribution to the field of health sciences librarianship in Canada.

The turn of the century was a time of turbulence, change, and reflection for the Association. In 1998, the association tried to address the need for a provincial health information network by publishing Access to Knowledge-Based Health Information in Manitoba: A Position Paper by the Manitoba Health Libraries Association. This paper addressed what the Association saw as a "growing problem of providing proper access to the health knowledge base for all Manitobans". The position paper outlined the recommendation to build a comprehensive health information network. While the health libraries in Winnipeg were experiencing major economic restructuring during the late 1990s, MHLA struggled with its purpose and identity. Core individuals, however, remained committed to the association and the work continued. Focusing on the Future, a re-visioning workshop, was held in 2001 to engage members in a discussion on what the association could be like in 3 years. In early 2002, a working group revised the MHLA constitution, which included a name change; the association became the Manitoba Association of Health Information Providers.

\section{References}

1. Kroeker R. The birth and growth of the Manitoba Health Libraries Association. Manitoba Library Association Bulletin. 1979; June:22-3.

2. Pritchard D. Manitoba Health Libraries Association part one: beginnings. MHLA News. 1986-1987;9(1): 5-7.

3. Pritchard D. Manitoba Health Libraries Association part two: the committee structure. MHLA News. 1986-1987; 9(2):10-4.

4. Pritchard D. Manitoba Health Libraries Association part three (conclusion): the broader scene. MHLA News. 19861987;9(3):11-3. 
This article has been cited by:

1. Giles-Smith Lori. 2011. Manitoba Association of Health Information Providers. Journal of the Canadian Health Libraries Association 32:3, 149. [Citation] [Full Text] [PDF] [PDF Plus]

2. 2011. Full issue in PDF / Numéro complet en form PDF. Journal of the Canadian Health Libraries Association 32:3, 133-184. [Citation] [PDF] [PDF Plus] 